\title{
REÚSO DE ÁGUAS CINZAS NA ESCOLA DE ENSINO MÉDIO DO CAMPO IRMÃ TEREZA CRISTINA: UMA PROPOSTA EM CONSTRUÇÃO
}

\author{
Luís Moreira de Oliveira Filho iD 1, Érikson Alves Soares iD 2 Maria Ivanilda de \\ Aguiar (D) 3, Olienaide Ribeiro de Oliveira Pinto iD 4
}

Resumo: O semiárido brasileiro é caracterizado pelas condições de escassez hídrica, com chuvas irregulares, concentradas em pequeno período e alta evaporação, o que demanda o desenvolvimento de tecnologias sociais. Nesse sentido, a EEM do Campo Irmã Tereza propos reúso das águas cinzas como instrumento laboratorial de pesquisa dos educandos no campo experimental. E essa proposta objetiva apresentar para as famílias dos educandos uma tecnologia de baixo custo que pode ser replicada nos seus quintais produtivos para amenizar a deficiência hídrica e maior segurança nutricional. Quanto ao gênero, a pesquisa é teórica por aprimorar teorías de educação do campo e empírica por oportunizar estudos a partir da vivência na temática por estes pesquisadores. A pesquisa foi exploratória, cujo objetivo foi o de buscar maior familiaridade com o problema proposto; é descritiva porque oportuniza descrever fatos e fenômenos da realidade que se busca estudar através de uma abordagem qualitativa. As informações coletadas e produzidas tiveram a participação e colaboração da gestão escolar e professor de OTTP através de questionário semiestruturado, utilizando-se do google formulário, coleta de documentos sobre a escola, consubstanciada pela pesquisa bibliográfica. A análise dos resultados mostrou que a proposta é viável e necessária para as comunidades dos territórios camponeses em face da escassez da água. Conclui-se a partir das análises da pesquisa de campo, que a proposta da utilização de águas cinzas no campo experimental está vinculada às condições de existência dos sujeitos do campo a partir de um processo de ensino contextualizado.

Palavras-chave: Bioágua; Educação do Campo; Tecnologias Sociais.

\section{REUSE OF GRAY WATER IN THE EEM AT CAMPO IRMÃ TEREZA CRISTINA: A PROPOSAL UNDER CONSTRUCTION}

\footnotetext{
${ }^{1}$ Mestrando em Sociobiodiversidade e Tecnologias Sustentáveis pela Universidade da Integração Internacional da Lusofonia Afro-Brasileira (UNILAB), Redenção-CE. Professor da Rede Pública Estadual do Ceará. Email: professorluismoreira@gmail.com.

${ }^{2}$ Graduado em Engenharia Ambiental pelo Instituto Federal de Educação, Ciência e Tecnología (IFCE). Professor da Escola do Campo Irmã Tereza. E-mail: erikson3045@gmail.com.

${ }^{3}$ Doutora em Ecologia e Recursos Naturais pela Universidade Federal do Ceará (UFC). Professora no Mestrado Acadêmico em Sociobiodiversidade e Tecnologias Sustentáveis da UNILAB, Redenção-CE, Brasil. E-mail: ivanilda@unilab.edu.br.

${ }^{4}$ Doutora em Agronomia/Fitotecnia pela Universidade Federal do Ceará (UFC). Realiza estágio de pós-doutorado como bolsista do Programa Nacional de Pós-Doutorado (PNPD)/CAPES vinculado ao (MASTS) da (UNILAB). E-mail: agron.olienaide@gmail.com.
} 
Abstract: The Brazilian semiarid region is characterized by conditions of water scarcity, with irregular rainfall, concentrated in a short period and high evaporation, which requires the development of social technologies. In this sense, the EEM at Campo Irmã Tereza proposed the reuse of gray water as a laboratory research tool for students in the experimental field. And this proposal aims to present to the families of the students a low-cost technology that can be replicated in their productive backyards to alleviate water deficit and greater nutritional security. As for gender, the research is theoretical for improving field education theories and empirical for providing opportunities for studies based on the experience in the subject by these researchers. The research will be exploratory, whose objective is to seek greater familiarity with the proposed problem; it is descriptive because it provides an opportunity to describe facts and phenomena of reality that one seeks to study through a qualitative approach. The information collected and produced had the participation and collaboration of the school management and OTTP teacher through a semi-structured questionnaire, using the google form, collection of documents about the school, substantiated by bibliographical research. The analysis of the results showed that the proposal is viable and necessary for the communities in the peasant territories in view of the scarcity of water. It is concluded from the analysis of field research, that the proposal to use gray water in the experimental field is linked to the conditions of existence of the subjects in the field from a contextualized teaching process.

Keywords: Biowater; Countryside Education; Social Technologies.

\section{Introdução}

A Região Nordeste (NE) do Brasil ocupa uma área de 1,56 milhão de $\mathrm{Km}^{2}$ e abriga por volta de 57 milhões de habitantes (IBGE, 2018;2019). Do ponto de vista político-administrativo esta região é composta por nove Estados, abrigando um total de $47,2 \%$ dos estabelecimentos rurais da agricultura familiar no País, em 2007. Com este total de estabelecimentos, o NE abriga em seu território 1.838 .846 trabalhadores da agricultura familiar. Recentemente a agricultura familiar se constitui na principal forma de produção e trabalho no campo, e que apesar da desigualdade da distribuição territorial, ainda conseguem manter uma boa produção (AQUINO, 2020).

Vale ressaltar que a região Nordeste está localizada em sua maior parte no semiárido brasileiro que segundo Malvezzi (2007), a despeito da escassez de água e das condições precárias de vida, é o mais chuvoso e o mais populoso do planeta. Outra característica dessa região é que o subsolo é formado em $70 \%$ de rochas cristalinas, rasas, o que vai aumentar as dificuldades para a formação de mananciais perenes e potabilidade da água, em sua maior parte salinizada.

Conforme Malvezzi (2007), a pluviosidade é em média 750 mm/ano, mas variando na região entre $250 \mathrm{~mm} / a n o$ a $800 \mathrm{~mm} / a n o$, no entanto a evaporação é de $3.000 \mathrm{~mm} / \mathrm{ano}$, sendo três vezes maior do que a pluviometria. Ainda segundo o autor, há déficit hídrico porque a chuva que cai 
é menor do que a água que evapora. Dessa forma, é necessário não somente armazenar água, mas também fazer o reúso das águas utilizadas, entre elas as águas cinzas.

Para amenizar o problema gerado pelo inadequado tratamento e disposição das águas cinzas ou águas de servir, ou servidas como as famílias preferem chamar e que são utilizadas nas propriedades rurais. São águas, que após passar por um tratamento poderão ser utilizadas nos quintais produtivos, por meio de uma tecnologia simples, também chamada como tecnologia social ou bioágua (SANTIAGO et al., 2012). Porém essa tecnologia ainda é pouco conhecida, necessitando ser mais difundida e utilizada.

Neste sentido, as escolas do campo podem contribuir para transmitir este e outros conhecimentos adaptados à realidade camponesa, como propõe, por exemplo, a política estadual de educação ambiental do Ceará, através da Lei 14.892/2011, que orienta as escolas situadas em áreas rurais a trabalhar a partir de temas, conforme incisos: conservação do solo; gestão dos recursos hídricos; desertificação; desmatamento e erosão; conhecimento sobre microbacias; proteção e conservação da biodiversidade; incentivo à agroecologia e convivência com o semiárido.

Nessa linha de pensamento, as Escolas do Campo têm colaborado na implementação da consciência ambiental, e preservação dos recursos naturais da região rural, pois além de terem a base curricular tradicional das escolas, possuem uma oferta de componentes curriculares voltados para o meio rural, sendo ensinados práticas de manejo e conservação do solo, e das águas, recuperação de áreas degradadas e meios sustentáveis de convivência com o semiárido. Esses conteúdos são ensinados por meios práticos, através do campo experimental, onde são aplicadas tecnologias e implementadas unidades produtivas, permitindo ao aluno desenvolver, na prática, conceitos adquiridos em sala de aula.

O intuito dessas escolas é fazer da zona rural um lugar produtivo, onde o aluno possa obter maneiras de se sustentar no campo e que segundo Molina e Freitas (2013, p. 3) a "Educação do Campo vincula-se à construção de um modelo de desenvolvimento rural que priorize os diversos sujeitos sociais do campo". Tudo isso pautado em preceitos agroecológicos e sustentabilidade que conforme Altieri (2004, p. 23) esta abordagem "integra os princípios agronômicos, ecológicos e socioeconômicos à compreensão e avaliação do efeito das tecnologias sobre os sistemas agrícolas e a sociedade como um todo".

Para Molina e De Jesus (2004, p. 16), uma Educação do Campo assume a ideia de que é necessário fazer do campo uma opção de vida, vida digna, evitando-se assim, o êxodo rural, com práticas sustentáveis, ou seja, que possam gerar renda e desenvolvimento regional, sem que haja uma degradação desenfreada dos recursos naturais. Por isso, uma tecnologia muito empregada para a reutilização de águas cinzas é o filtro biológico, comumente chamado de bioágua, que de acordo com Costa e Bessa (2019) "é um simples mecanismo capaz de filtrar as águas cinzas dos domicílios com processos físicos e biológicos". 
Vale descrever que essa tecnologia consiste em um tanque composto por camadas de húmus, minhocas, serragem, areia lavrada, cascalhos e seixos. Sendo levado por gravidade até o tanque de reúso, que por sua vez é destinada para o meio produtivo, comumente, localizado no quintal da casa. Além do mais, os quintais produtivos, de acordo com Pedrosa (2016), são espaços das pequenas propriedades em que as famílias cultivam plantas alimentícias, ornamentais, leguminosas e medicinais que já são muito implementados hoje em dia nas comunidades rurais, no entanto, possuem um fator limitante que é a disponibilidade de água para suprir a demanda hídrica da plantação, para seu desenvolvimento saudável.

Neste sentido, como uma das tecnologias incentivada pelas escolas do campo, a reutilização das águas cinzas de acordó com o conceito desenvolvido no projeto bioágua: reúso das águas cinzas para a produção de alimentos no semiárido da EEM do Campo Florestan Fernandes é uma tecnologia, conforme figura 1 que torna a água da lavagem da louça e do banho dos estudantes pronta para uso na irrigação de fruteiras e hortaliças. A água já servida, como costuma ser chamada pelas famílias agricultoras do Semiárido é conhecida como água cinza pela sua aparência turva devido à presença de resíduos de alimentos e produtos de limpeza

Vale ressaltar informações sobre o projeto do bioágua da EEM Florestan Fernandes, tendo em vista que as escolas do campo de ensino médio do estado do Ceará atuam em redes para fortalecer o currículo diferenciado às necessidades dos sujeitos do campo. E que por isso, o projeto da referida escola busca gerar informações sobre o sistemas bioágua no que se relaciona a oferta de água cinza, produto de alimentos, manejo de filtro e manejo do sistema produtivo. Dessa forma, essa tecnologia é importante para disseminar conhecimentos entre os agricultores da agricultura camponesa na região do semiárido.

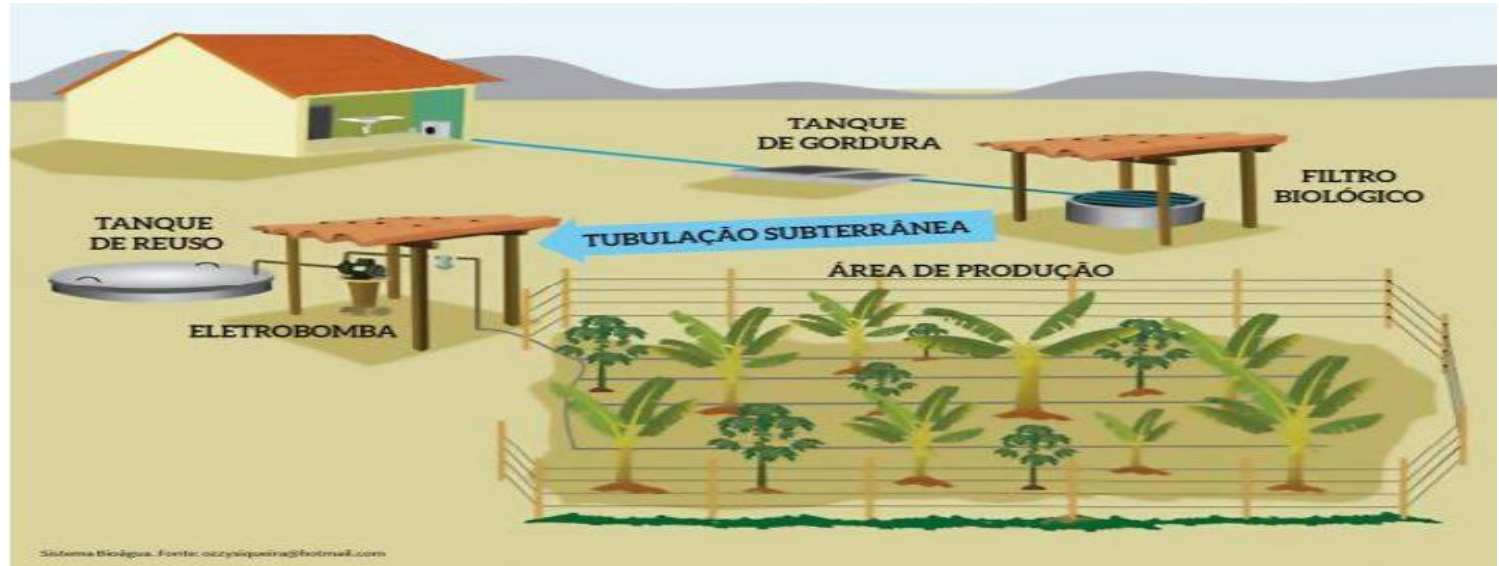

Figura 1: Projeto Bioágua: reúso das águas cinzas para produção de alimentos no semiárido (Experiência na Escola Florestan Fernandes - Assentamento Santana).

Fonte: EEM Florestan Fernandes.

Com base nessa contextualização e problematização essa investigação é importante por oportunizar conhecer o trabalho e pesquisa como princípio educativo no campo experimental da escola no desenvolvimento e produção de 
tecnologias de baixo custo de implantação, manejo e manutenção para os educandos e suas famílias. Ressalta-se a importância da proposta do bioágua como espaço de aprendizagem e práticas de princípios agroecológicos integrados às áreas do conhecimento em que os alunos possam aprender assuntos como ciclagem de nutrientes e manejos do solo e da água (SANTIAGO et al., 2015).

Portanto, este trabalho tem como objetivos: 1) mostrar como a proposta do reúso de água cinzas no campo experimental da Escola Irmã Tereza Cristina pode contribuir para as comunidades do assentamento Nova Canaã em que está inserida a escola; 2) revelar como o uso do bioágua pode amenizar a deficiência hídrica na região, e ajudar na melhoria da qualidade de vida dos moradores camponeses.

A maior parte do território do Ceará, ou seja, 86,9\% está inserida na área do semiárido com um regime de chuvas irregulares e concentradas, tendo duas estações definidas: período chuvoso (janeiro a junho) que se subdivide em: pré-estação chuvosa (janeiro); estação chuvosa (fevereiro a maio); pós estação-chuvosa (junho) e o período seco de julho a Dezembro (CEARÁ, 2008).

Sabe-se que o clima do semiárido cearense tem suas peculiaridades, com riscos de secas, taxa de evapotranspiração muito alta, solos rasos, pouco permeáveis. No entanto, os problemas do semiárido nordestino são mais políticos, econômicos e educacionais do que pelas questões climáticas e do seu solo cristalino em que se aflora a rocha e pedras nos solos escaldados pelas altas temperaturas com insolação intensa (2.800 horas por ano) e taxas elevadas de evapotranspiração (CEARÁ, 2008).

Para Malvezzi (2007) o segredo da convivência do semiárido é compreender como o clima funciona e fazer adaptações de forma inteligente porque não se trata mais de "acabar com a seca", mas de perceber que é possível melhorar a vida nessa região a partir do desenvolvimento de tecnologias simples como cisternas de placas encravadas no solo e outras tecnologias que estão sendo testadas e divulgadas como a reutilização das águas cinzas das propriedade rurais.

Nessa linha de pensamento, Conti e Pontel (2013) discorrem que a convivência oportuniza uma transformação porque possibilita tecer relações entre os seres humanos e a natureza para a melhoria de vida das famílias camponesas. E também por possibilitar que os sertanejos possam perceber as potencialidades e limites das características do semiárido, desterritorializando as culpas atribuídas às condições naturais e também exterminar a indústria da seca conforme explica Malvezzi (2007) que o objetivo de uma "política educacional seja pautada pelo ensino da convivência com o semiárido, não para a manutenção da indústria da seca". Então, como observam Silva et al. (2020), a seca foi uma "oportunidade para obtenção de recursos para criação de estradas e açudes enquanto que a população faminta definhava. Os sertanejos tornaram-se veículo para a entrada de financiamentos em um projeto político liberal".

\section{Referencial teórico}




\subsection{Do Campo Experimental aos quintais produtivos}

Silva et al. (2020) observam que a escassez de água no semiárido é um desafio permanente para o desenvolvimento de plantio, afinal, como manter os quintais produtivos dependentes apenas do regime de chuvas no período seco? Os autores respondem que a solução é o desenvolvimento de tecnologias sociais, entre elas, aponta-se o aproveitamento das águas cinzas das residências camponesas para a manutenção dos quintais produtivos a partir do reúso de águas dessas águas no campo experimental, para o desenvolvimento de tecnologias na Escola Irmã Tereza, que está em processo de implementação. Sobre quintais é importante destacar este conceito em Neto et al. (2019, p. 3):

Os quintais são sistemas que atuam como uma estratégia de uso mais sustentável dos recursos medicinais por conservarem também as espécies nativas, especialmente os rurais, os urbanos são locais ricos em diversidade vegetal e de conservação da biodiversidade, além da propagação de saberes tradicionais.

O Campo Experimental da Agricultura Camponesa e da Reforma Agrária é uma estratégia política e pedagógica cuja finalidade é possibilitar desenvolver experiências educativas ligadas aos objetivos escolares e para tecnologías de convivência com o semiárido e a agricultura camponesa. Além do mais, as atividades no campo experimental são desencadeadas a partir do componente curricular Organização do Trabalho e Técnicas Produtivas (OTTP), articulando-se com as áreas do conhecimento e potencializando suas aplicações nos quintais das famílias dos alunos, conforme orienta o Projeto Político Pedagógico das Escolas do Campo de Ensino Médio do Estado do Ceará.

Como a EEM do Campo Irmã Tereza está em processo de construção do seu projeto político pedagógico é imperativo destacar o que orienta, por exemplo, o projeto político pedagógico da EEM do Campo João dos Santos de Oliveira (2020) sobre o componente curricular (OTTP) que está sob a mesma coordenação da $12^{a}$ Coordenadoria Regional de Desenvolvimento da Educação - CREDE 12 - que a EEM do Campo Irmã Tereza "o trabalho como princípio educativo deverá estar presente em todos os componentes curriculares; articular o conhecimento escolar com o trabalho produtivo e socialmente útil".

Vale ressaltar que o Campo Experimental da Escola do Campo Irmã Tereza consiste num território do ensino, da experimentação, da pesquisa da construção de novas alternativas tecnológicas, da organização coletiva, da cooperação para o trabalho, de experimentação do novo campo em construção: da agroecologia, da sustentabilidade ambiental, da soberania alimentar, da economia solidária, da convivência com o semiárido e da resistência cultural.

Nesse sentido, esta orientação do Campo Experimental da EEM do Campo Irmã Tereza vai ao encontro do documento orientador "Sistematização do Campo Experimental" da EEM João dos Santos de Oliveira quando orienta: "o campo experimental consiste em ser educativo, no despertar e vivenciar 
com os educandos a apreensão dos conhecimentos existentes das técnicas agrícolas, agroecológicas, valorizando as experiências produtivas existentes, visando à socialização prática dos conhecimentos apreendidos com as famílias dos estudantes das comunidades da região"

\subsection{Escolas do campo e a construção de educação do campo}

De acordo com o Decreto no 7.352 de 04 de Novembro de 2010, que dispõe sobre a política de educação do campo e o Programa Nacional de Educação na Reforma Agrária - PRONERA, no seu inciso II, a escola do campo é "aquela situada em área rural, conforme definida pela Fundação Instituto Brasileiro de Geografia e Estatística - IBGE, ou aquela situada em área urbana, desde que atenda predominantemente a populações do campo".

Para Caldart (2002), quando se fala em Uma Educação do Campo, reafirma-se articulação integrada entre duas lutas necessárias: ampliar o direito à educação e à escolarização no campo e pela construção de uma escola no campo, mas que também seja do campo. No: o povo tem direito de ser educado no lugar em que vive; Do: o povo tem direito a uma educação pensada desde o seu lugar e com sua participação, vinculada à sua cultura e às suas necessidades humanas e sociais.

Segundo a Resolução CNE/CEB de no 1 de 3 de abril de 2002, que institui as Diretrizes Operacionais para a Educação Básica nas Escolas do Campo, art. 20 , parágrafo único o qual afirma que:

a identidade da educação do campo é definida pela sua vinculação, ancorando-se na temporalidade e saberes próprios dos estudantes, na memória coletiva que sinaliza futuros, na rede de ciência e tecnologia disponível na sociedade e nos movimentos sociais em defesa de projetos que associem as soluções exigidas por essas questões à qualidade social da vida coletiva no País.

Neste sentido, Pereira, Costa e Paula (2020) ressaltam que a educação do campo é um espaço de disputa em que é preciso conquistar uma escola do campo que esteja articulada com as necessidades dos sujeitos do campo, os camponeses, e que se reverbere nas necessidades da classe trabalhadora. Reverberadas nestas ideias das autoras supracitadas, Santos e Neves (2012) observam que a Educação do Campo é diferenciada da escola rural por ter sua identidade construída por e para os diferentes sujeitos do campo, além das práticas sociais, territórios e cultura que são alicerces do campo, ou seja, uma escola construída para os sujeitos no e do campo, no qual vivem e trabalham.

2.3 A Escola do Campo Irmã Tereza, sua história e sua identidade em construção

A Escola do Campo Irmã Tereza Cristina é fruto da luta da organização dos movimentos sociais, principalmente do Movimento dos Trabalhadores Rurais Sem Terra (MST) para ampliar e garantir direitos expressos na 
Constituição de 1988 para a melhoria da educação dos sujeitos que moram no campo.

A Conquista da escola se deu em vários processos de lutas, manifestações, audiências, priorizando uma concepção de Educação do Campo com currículo e metodologias adequadas às necessidades da população do campo cearense. Além do mais, a escola está em processo de estruturação e funcionamento após o seu primeiro ano de existência iniciado em 2020 e afetada pela pandemia da covid-19.

A Escola, situada no Assentamento Nova Canaã, recebeu o nome de Irmã Tereza Cristina em homenagem a essa mulher, freira que viveu por muitos anos em Quixeramobim-CE, por sua história de vida voltada às lutas sociais nas áreas de assentamento durante sua vida pastoral. Particularmente ela acompanhou o Assentamento Nova Canaã desde o processo de ocupação até o dia em que ocorreu a emissão de posse por parte do Instituto Nacional de Colonização e Reforma Agrária - INCRA.

Vale ressaltar que escola é pública, fazendo parte da organização do Estado do Ceará, tendo sua estrutura educacional acompanhada e orientada pela $12^{a}$ Coordenadoria de Educação do Ceará de Quixadá - CREDE 12. Sua proposta pedagógica é elaborada com a participação dos diversos sujeitos do campo do Ceará, universidades, movimentos sociais e ONGs parceiras.

A escola tem como estratégia pedagógica os seguintes componentes curriculares integradores da parte diversificada: pesquisa de estudo e pesquisa (PEP), cuja orientação é estudo da realidade e pesquisa como princípio educativo; organização do trabalho e técnicas produtivas (OTTP), tendo como foco o trabalho como princípio educativo, articulação entre a educação e o trabalho produtivo socialmente; práticas sociais e comunitárias (PSC), objetivando a organização coletiva, participação social e política através da mística e animação da cultura camponesa.

A escola também tem como estratégia, a realização do inventário da realidade, que objetiva orientar a gestão da escola, orientar a formação e trabalho dos educadores (as), mas principalmente conhecer a realidade para transformá-la e também a estratégia do campo experimental que é laboratório para integração da teoria-prática nos estudos sobre o trabalho, sendo uma área de produção vinculada ao currículo da escola através das unidades produtivas. Objetiva também, produzir e disseminar tecnologias adequadas e de baixo custo para as famílias camponesas dos territórios do assentamento, entre elas, o reúso de águas cinzas para os quintais produtivos.

2.4 Sustentabilidade e convivência no semiárido nas comunidades camponesas do sertão cearense

Entende-se por sustentabilidade segundo Miller Jr (2008, p. 3) "a capacidade que os sistemas da Terra, incluindo as economias e sistemas culturais humanos, têm de sobreviver e se adaptarem às condições ambientais em mudanças". E por isso, ela é composta por capital natural e sua degradação, soluções e compromissos dos indivíduos que habitam comunidades, principalmente no campo. 
Guimarães (2009) escreve que a sustentabilidade é um campo em disputa pela gravidade da crise ambiental em que o discurso dominante busca consolidar a preservação da ordem estabelecida de um lado, de outro, à crítica necessária ao discurso desenvolvimentista pela abordagem econômica. Para o referido autor, o que se busca é uma sustentabilidade para além dos paradigmas desenvolvimentistas que considerem uma mudança no coração humano e que permitam reconhecer o ambiente como realidade complexa para potencializar o equilíbrio socioambiental e criação de sociedade sustentável que segundo Miller Jr. (2008, p.3) atende do ponto de vista ambiental:

Às necessidades atuais de sua população em relação aos alimentos, água, e ar limpos, abrigo e outros recursos sem comprometer capacidade de as gerações futuras de atenderem suas necessidades. Viver de forma sustentável significa sobreviver da renda natural fornecida pelo solo, pelas plantas, pelo ar e pela água e não exaurir ou degradar as dotações de capital natural da Terra, que fornecem essa renda biológica.

Já Sachs (1993, p.38) destaca cinco dimensões para a sustentabilidade que todo planejamento deve levar em conta:

a) Sustentabilidade social em que a meta é criar uma civilização com maior equidade na distribuição de renda e de bens para a reduzir as desigualdades sociais;

b) Sustentabilidade econômica que deve estar focada no melhor gerenciamento dos recursos e de fluxo de investimentos públicos e privados, com melhore eficiência avaliada em termos macrossociais do que rentabilidade;

c) Sustentabilidade ecológica - utilizar os recursos naturais com o mínimo de danos aos sistemas de sustentação da vida e definir normas para adequada proteção ambiental;

d) Sustentabilidade espacial - obter uma configuração rural-urbana mais equilibrada e uma melhor distribuição territorial dos assentamentos humanos;

e) Sustentabilidade cultural - buscar raízes endógenas de processos de modernização e de sistemas agrícolas integrados, processos que busquem mudanças dentro da continuidade cultural e que traduzam o conceito de ecodesenvolvimento em um conjunto de soluções específicas para o local, ecossistema, a cultura e a ética.

Nesse sentido, a sustentabilidade é uma ideia, uma referência, que avaliada a partir dos diagnósticos e propostas de soluções para as questões ambientais, toma formas de ação humana (BRASIL, 2002). Nesse contexto, Alcóver et al. (2020) e Pinto et al. (2020) discorrem que a convivência com o semiárido é um campo de possibilidades de resgate das relações entre seres humanos e natureza através da difusão de tecnologias sustentáveis pelas populações camponesas que sofrem com os efeitos da escassez d'água e de outros desafios econômicas e socioambientais na região. 
No material semeando saberes, inspirando soluções: boas práticas na convivência com o semiárido, pode-se compreender melhor o conceito de sustentabilidade a partir da experiência do reúso de águas cinzas por agricultores na região do Cariri-Paraíba, através do projeto Diagnóstico e e instalação e tecnologias de reutilização de águas servidas Ilca (2017). E que colabora com a proposta da Escola Irmã Tereza no desenvolvimento desta tecnologia social, do campo experimental para difusão dessa tecnologia para os quintais produtivos no assentamento rural Nova Canaã em que a escola está localizada.

De acordo com Lopes et al. (2013), a escassez hídrica torna necessária a difusão de tecnologias alternativas, entre elas, o reúso de águas no semiárido, que de forma planejada, pode ser fonte hídrica alternativa na produção agrícola. Diz os autores: "reúso de águas pode ser definido como uma prática onde a água, após ser utilizada para um determinado fim, é reutilizada, ou reaproveitada após receber um determinado tratamento" (LOPES, et al., 2013, p. 217). Segundo Fiori, Fernandes e Pizzo (2006) o "reúso da água é a reutilização da água, que, após sofrer tratamento adequado, destina-se a diferentes propósitos, com o objetivo de preservar os recursos hídricos existentes e garantir a sustentabilidade".

Por fim, colaborando e acrescentando reflexões teóricas nesse tema é importante destacar as reflexões do prof. Joaquim Lopes no prefácio do livro "Convivência com o Semiárido" (2020) que as tecnologias sociais, relegadas como políticas públicas, são um alternativa para convivência com o Semiárido por possibilitar ações simples e eficazes de baixo custo que transformam o ambiente em que se vive, onde a aridez e escassez são regras. Tecnologias que estejam ao alcance das populações e que lhes permitam qualidade de vida no campo, principalmente em áreas de assentamento rural.

\section{Metodologia}

Quanto ao gênero (Demo, 2000), essa pesquisa foi teórica porque possibilitou aprimorar ideias e teorias na área de educação do campo e empírica por oportunizar momentos de estudos a partir da experiência e vivência destes pesquisadores na coleta de dados com os sujeitos da pesquisa que têm envolvimentos com o tema. Quanto aos objetivos (Gil, 2002), a pesquisa foi exploratória, cujo objetivo foi buscar maior familiaridade com o problema proposto e também descritiva porque possibilitou descrever fatos e fenômenos da realidade que se busca estudar neste trabalho sobre a importância do desenvolvimento de propostas de tecnologías no campo experimental que possam ser disseminadas para as comunidades do assentamento.

A abordagem da pesquisa foi descritiva porque segundo Godoy (1995, p.21) é um "fenômeno que pode ser melhor compreendido no contexto em que ocorre e do qual é parte, devendo ser analisado numa perspectiva integrada". Além do mais, há uma proximidade destes pesquisadores com o fenômeno estudado. $E$ quanto aos procedimentos metodológicos/técnicos, conforme 
classificação de Gil (2002), essa pesquisa foi bibliográfica, tendo como fonte de informação a pesquisa de campo (FONSECA, 2002).

As técnicas e instrumentos de coleta de dados foram o questionário semiestruturado com oito questões direcionadas ao diretor, coordenadora escolar e professor de Organização do Trabalho e Técnicas Produtivas. 0 questionário foi aplicado através do Google Forms e, também, foi realizada análise de documentos da EEM Irmã Tereza Cristina a partir da análise de dados qualitativos, a análise do discurso, ou seja, a análise das respostas dos sujeitos da pesquisa que são o grupo gestor da referida escola. Também foram realizadas coletas de documentos nas EEM João dos Santos de Oliveira que está localizada no assentamento 25 de Maio no município de Madalena-CE e EEM Florestan Fernandes localizada no assentamento Santana do município de Monsenhor Tabosa, escolas que já têm doze anos em funcionamento de suas propostas de educação do campo

As informações coletadas e produzidas tiveram a participação e colaboração da gestão escolar, através do diretor e coordenadora escolar que se prontificaram em fornecer documentos e informações sobre a escola e seus projetos. Também teve a colaboração fundamental do profesor Erikson, professor de Organização, Técnicas e Trabalho Produtivo (OTTP) e que colabora na autoria deste trabalho. Também tiveram a colaboração dos gestores das outras duas escolas já descritas.

E importa esclarecer que se fez referência aos sujeitos da pesquisa como educadores e educadoras como está orientado na pedagogia da escola do campo e que de acordo com Caldart, (2002, p .25), "educador é o que desenvolve o seu trabalho docente de fazer e pensar a formação humana na escola". E que portanto, é um conhecedor da pedagogia do campo e da complexidade dos processos de aprendizagem para o desenvolvimento da juventude estudantil campesina e para o fortalecimento da identidade do povo camponês.

\section{Resultados e discussões}

4.1 Localização e caracterização da área da EEM do Campo Irmã Tereza

A Escola de Ensino Médio (EEM) do Campo Irmã Tereza Cristina (Figura 2), está localizada a $20 \mathrm{Km}$ da Zona Urbana da Cidade de Quixeramobim, no assentamento Nova Canaã. O município de Quixeramobim dista $183 \mathrm{Km}$ de Fortaleza, capital, do Ceará, possui em torno de $39,59 \%$ de sua população vivendo na zona rural (IPECE, 2017) e está localizada na mesorregião dos sertões cearenses, microrregião Sertão de Quixeramobim. 


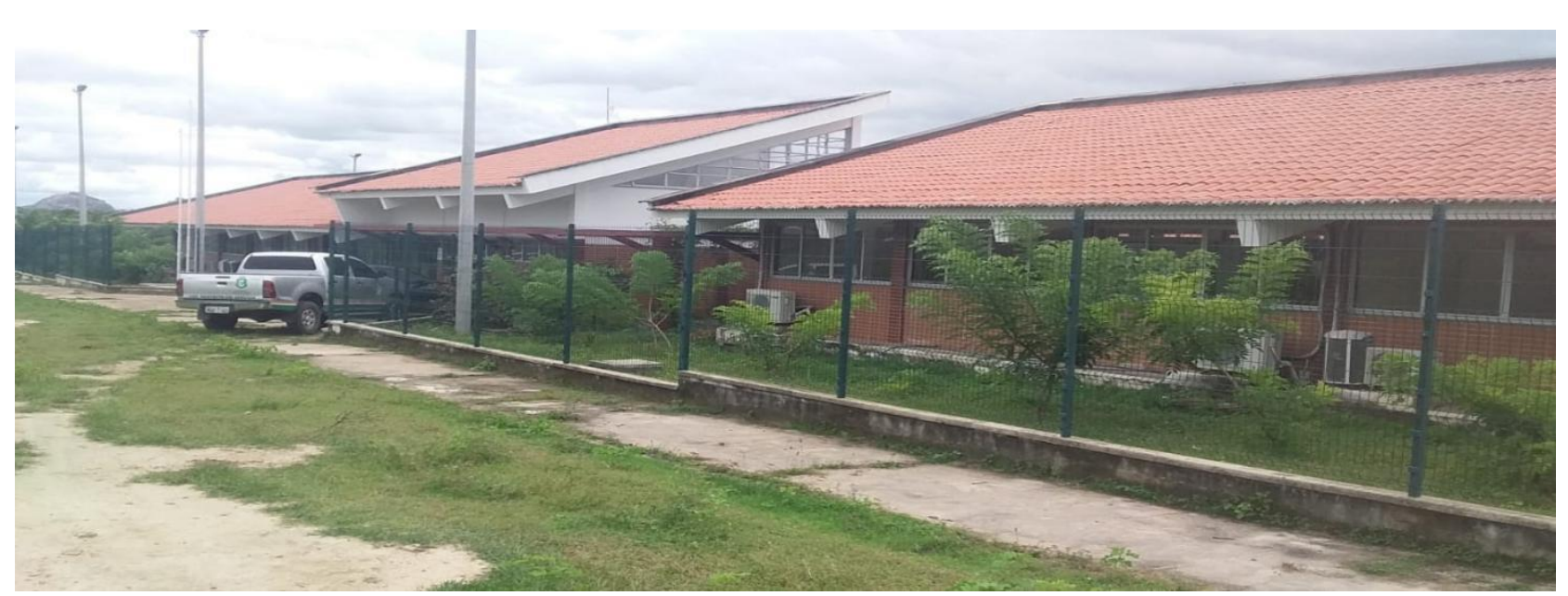

Figura 2: EEM do Campo Irmã Tereza Cristina.

Fonte: Os autores, 2021.

Ao todo, a escola atende um público de 129 estudantes, provenientes dos Assentamento Nova Canaã, que abriga 85 famílias, e da região circunvizinha (Muxuré Velho, Jundiá, Encantado, Lacerda, Pau Ferro e Estrela). Assim como a maioria das Escolas do Campo, a EEM do Campo Irmã Tereza Cristina foi obtida através da luta dos trabalhadores da reforma agrária e iniciou suas atividades letivas em fevereiro de 2020 (SEDUC, 2020).

4.2 Proposta do Sistema de Reúso de Água em processo de implantação no campo experimental da EEM Irmã Tereza

As dificuldades das famílias camponesas de se manterem nos seus territórios é ainda uma realidade e um desafio a ser enfrentado. Por isso, muitos jovens deixam as suas comunidades para trabalharem em fábricas nas grandes cidades, inchando as periferias e isso é colaborado pela ausência de tecnologias sociais para a convivência com o semiárido, principalmente nas áreas de assentamento rural afetadas pela ausência de políticas públicas de convivência com o semiárido.

Nesse sentido, uma Escola do Campo tem o desafio de colocar em prática a concepção de Educação do Campo para desenvolver um currículo integrado para a formação do homem e da mulher camponesa de um lado, de outro, a promoção do desenvolvimento do território camponês a partir da disseminação de tecnologias sociais de convivência com o semiárido e agricultura camponesa experienciado pelos educandos no campo experimental.

A pesquisa contou com a participação do diretor, coordenadora escola e professor de Organização do Trabalho e Técnicas produtivas que, doravante intitulados nessa pesquisa como educador(a) 1, educador(a) 2 e educador(a) 3 nessa ordem. Dessa forma, para o educador 1 a proposta do reúso das águas cinzas (bioágua) teve origem em entidade não governamental e que será melhor implementada quando do retorno das aulas presenciais. E que nos modos de vivência da sociedade, em que impera o consumismo, é necessário políticas que colaborem na manutenção dos mananciais de água.

Já o educador(a) 2 discorre que essa proposta vai contribuir nos estudos e experimentos das escolas do campo do Ceará e nas experiências já (c) (1) $(9$

Perspectivas em Diálogo, Naviraí, v. 8, n. 18, p. 99-122, jul/dez. 2021. 
vividas na área agroecológica apoiadas pela SEDUC. E o educador(a) 3 argumenta que a EEM do Campo tem em seus ensinamentos a agroecologia, e leva em consideração as peculiaridades das regiões, como nossa região tem deficiência hídrica, é uma proposta das Escolas do Campo que se trabalhe o tema do reúso de água. $\mathrm{E}$ através de um projeto realizado pelo grupo Centro de Estudos do Trabalho e de Assessoria ao Trabalhador - CETRA - no qual a escola foi contemplada com esse projeto, foi possível a construção do filtro e demais componentes que o integram para assim podermos mostrar que é possível fazermos o reúso e produzir alimentos saudáveis.

Esses discursos iniciais dos sujeitos da pesquisa se reverberam na perspectiva de educação para o campo, conforme Santos e Neves (2012), discorrem sobre uma educação diferenciada que considere: "os diferentes sujeitos do campo, práticas sociais, territórios e culturas" Segundo as autoras, essa educação diferenciada cria e recria as condições de permanência no campo,e portanto, a "educação é uma estratégia importante para a transformação da realidade dos sujeitos do campo, em todas as suas dimensões (sociais, ambientais, culturais, econômicas, éticas, políticas) (SANTOS; NEVES, 2012).

Ao indagar sobre a proposta do campo experimental da escola para os quintais produtivos das comunidades do assentamento, o educador (a) 1 argumentou que as aulas práticas estimulam cada vez mais os estudantes a descobrir coisas novas. E apesar de ser um conteúdo bastante difundido ainda é ignorado por parte da maioria dos nossos estudantes. Assim o trabalho no campo experimental, com as disciplinas diversificadas, será difundido junto aos estudantes e aí temos a expectativa de os mesmos disseminarem os conhecimentos nos quintais de sua comunidade e residências. Para 0 educador(a) 2 existem os núcleos de base no Assentamento; são grupos de famílias organizadas por caracterização ou proximidades. E complementa o educador(a) 3 que através da conscientização e mostrando, na prática, que é uma tecnologia que tem excelentes resultados.

Nessa linha de pensamento dos sujeitos da pesquisa, Caldart (2009) argumenta que a uma escola do campo pressupõe profissionais com 0 compromisso de coordenar a arquitetura de um currículo que contemple as dimensões formativas, articulando o trabalho pedagógico na dimensão do conhecimento com práticas de trabalho, cultura e luta social. Discorre ainda a pesquisadora que é fazer uma escola vinculada à vida real dos educandos, ou seja, o vínculo entre educação e trabalho que é questão central com práxis e como princípio educativo.

Nesse sentido, quando perguntado sobre a finalidade da proposta de bioágua, na escola é apenas uma opção de escolha, percebeu-se que a proposta precisa ser melhor pensada e articulada no coletivo da gestão a partir do projeto político pedagógico da escola (Figura 3) que trata sobre os objetivos do bioágua no campo experimental. E que todas as opções propostas neste item do questionário devem ser pensadas de forma sistêmica, articulando escola e comunidade, campo experimental, unidades produtivas, com a questões materiais de existência das famílias que passam por momentos de vulnerabilidade social, não apenas pelas questões climatológicas, mas também 
pelas questões políticas, econômicas para se efetivar a convivência do homem camponês em seus territórios.

Conforme essas argumentações dos sujeitos da pesquisa, Molina e Freitas (2011) observam que os processos de ensino e aprendizagem não podem se desenvolver desacoplados da realidade dos seus educandos. Dessa forma, para as referidas autoras é necessário internalizar no trabalho pedagógico à materialidade da vida dos educandos em que se abrem as possibilidades de ressignificar conhecimentos

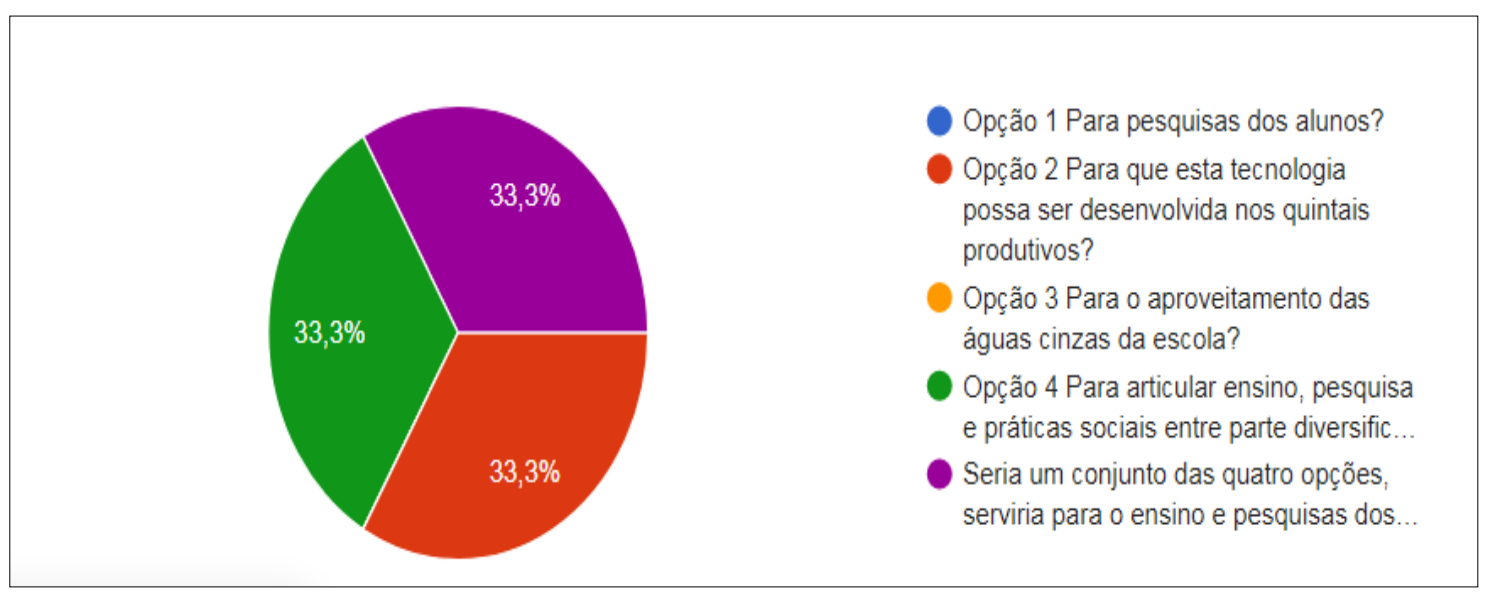

Figura 3: Finalidade da proposta de bioágua no campo experimental.

Fonte: os autores, 2021.

No entanto, é imperativo reconhecer que a proposta está bem encaminhada enquanto estratégia de ensino, pesquisa, produção de conhecimento, objetivos e resultados esperados na seguintes questões respondidas pelos sujeitos da pesquisa quanto aos objetivos:

Articular ensino, pesquisa e práticas sociais entre os educandos e suas famílias (EDUCADOR(A) 1). Expandir a tecnologia para os quintais produtivos; Desenvolver a pesquisa entre os alunos; Aproveitar as águas cinzas da agroindústria. Promover atividades, práticas, extraclasse que sejam produtivas e que possam estar complementando o ensino e aprendizado do aluno, além de produzir alimentos no qual serão utilizados na própria escola e comunidade, com o objetivo de difundir a tecnologia. (EDUCADOR(A) 2)

Além do mais, esta proposta, o reúso de água cinza na escola do campo, a partir do campo experimental não é apenas viável, mas necessária para as comunidades dos territórios camponeses em face da escassez da água pela importância de melhorar a produtividade nos quintais produtivos, o que colabora as falas do educador (a) (3) da pesquisa, quando se perguntou sobre a proposta ser levada para os quintais produtivos das comunidades do assentamento rural Nova Canaã em que a escola está inserida:

As aulas práticas estimulam cada vez mais os estudantes a descobrir coisas novas. E apesar de ser um conteúdo bastante difundido ainda é ignorado por parte da maioria dos nossos estudantes. Assim, o trabalho 
no campo experimental com as disciplinas diversificadas, será difundido junto aos estudantes e aí temos a expectativa de os mesmos disseminarem os conhecimentos nos quintais de sua comunidade e residências.

Percebe-se na fala do educador (a) 3 que o sentido da educação é instaurar novos mundos como tão bem discorre Freire (1996, p.28) quando discorre que "a capacidade de aprender, não apenas para nos adaptar, mas sobretudo para transformar a realidade, para nela intervir, recriando- a." Observa ainda o mestre: "é o saber da História como possibilidade e não como determinação. O mundo não é. O mundo está sendo" (FREIRE,1996, p. 30)

Nesse sentido, o campo experimental da escola camponesa é um instrumento importante de espaço educativo para produção de conhecimentos integrados com os saberes locais, mas também um campo de possibilidades para desenvolver tecnologias sociais de convivência com o semiárido nos territórios camponeses, conforme orientam os Projetos Políticos Pedagógicos das Escolas do Campo Florestan Fernandes e EEM do Campo João dos Santos de Oliveira. Dessa forma, colabora os sujeitos da pesquisa sobre a experiência da tecnologia de baixo custo para a reutilização das águas cinzas:

Através de visitação e demonstração da utilidade, relatos dos educadores e técnicos que conhecem a experiência e demonstração dos benefícios que essa prática traz para a comunidade e para as famílias. (EDUCADOR(A) 1). Mostrando que o sistema funciona, e que eles podem produzir muito utilizando uma água que seria descartada, além de mostrar que seria uma tecnologia de baixo custo. Sendo assim, a comunidade iria produzir alimentos saudáveis com um custo reduzido e sendo produzido no próprio quintal de casa. (EDUCADOR (A) 2). Esse processo vai contribuir para o uso racional da água e consequentemente a produção de frutas, hortaliças e plantas medicinais para o consumo das famílias, o que representa uma melhoria na qualidade de vida dessas pessoas. (EDUCADOR (A) 3).

Nessas falas dos sujeitos da pesquisa, Caldart (2003) observa que é preciso que a escola do campo e seu coletivo de educadores envolvam educandos e suas famílias em seu processo de educação e ensino, recriando estratégias que segundo a pesquisadora:

Construir o ambiente educativo de uma escola é conseguir combinar num mesmo movimento pedagógico as diversas práticas sociais que já sabemos ser educativas, exatamente porque cultivam a vida como um todo: a luta, o trabalho, a organização coletiva, o estudo, as atividades culturais, o cultivo da terra, da memória, dos afetos (CALDART, 2003, p. 73).

Nessa linha de pensamento, um ambiente educativo de práticas sociais oportuniza que tecnologias sociais de baixo custo experienciadas pelos educandos no campo experimental podem amenizar a deficiência hídrica e contribuir para a melhoria da qualidade de vida dos moradores nos territórios dos assentamentos rurais a partir do aproveitamento das águas que a família utiliza do chuveiro, da pia da cozinha, do tanque ou máquina de lavar. 
Dessa forma, as águas cinzas, que após tratadas podem ser usadas para o cultivo de plantas medicinais, hortas e plantas frutíferas nos quintais produtivos. Importa considerar que o sistema de reúso é uma tecnologia de convivência com o semiárido na qual reutiliza águas cinzas, que são águas geradas, neste caso, de toda a escola, com exceção dos vasos sanitários e mictórios (SANTIAGO et al, 2013).

Também a água tratada contribuirá para nutrir os solos dos quintais produtivos, aumentando a produção, evitando que as águas cinzas possam correr a céu aberto, reduzindo o gasto com o cuidado dos quintais produtivos que na maioria das vezes reforçam a capacidade de nutrição das famílias camponeses, principalmente em época de poucas chuvas no período da estação seca. E por fim, percebe-se nesta proposta do reúso das águas cinzas a construção em processo da identidade de uma escola voltada para a população camponesa, conforme as seguintes falas sobre os objetivos do desenvolvimento dessa tecnologia social no campo experimental da escola:

Articular ensino, pesquisa e práticas sociais entre os educandos e suas famílias; Expandir a tecnologia para os quintais produtivos; Desenvolver a pesquisa entre os alunos; Aproveitar as águas cinzas da agroindústria (EDUCADOR (A) 1). Promover atividades, práticas, extraclasse que sejam produtivas e que possam estar complementando o ensino e aprendizado do aluno, além de produzir alimentos no qual serão utilizados na própria escola e comunidade, também tem o objetivo de difundir a tecnologia (EDUCADOR (A) 2). Esse processo vai contribuir para o uso racional da água e consequentemente a produção de frutas, hortaliças e plantas medicinais para o consumo das famílias, o que representa uma melhoria nas qualidades de vida dessas pessoas (EDUCADOR (A) 3).

Percebe-se nessas falas dos sujeitos da pesquisa uma necessidade de educação que articula ensino com a realidade local a ser transformada e que nas palavras de Vendramine (2007, p. 129), uma educação do campo é necessária para além dos muros da escola quando tem como:

\begin{abstract}
Sustentação o reconhecimento de uma realidade de trabalhadores e trabalhadoras que têm resistido para continuar produzindo sua vida no espaço rural. $E$, especialmente, o reconhecimento de que esta realidade precisa ser alterada, tendo em vista a crescente pobreza, o desemprego, as grandes desigualdades sociais e as dificuldades de acesso às políticas públicas (saúde, educação, transporte, infraestrutura etc.). Portanto, pensar um projeto de educação do campo pressupõe a sua sustentabilidade em termos econômicos, sociais e culturais.
\end{abstract}

Sobre como a proposta do bioágua será trabalhada de forma integrada no currículo nas áreas da parte diversificada, destaca-se fala do educador (a) 2 quando argumenta que "m OTTP pode ser trabalhado a parte técnica, onde o aluno aprenderá o funcionamento e a produção através do reuso, em PEP o aluno aprenderá a fazer pesquisas na área e escrever projetos baseados no reúso, e PSC serviria para difundir a tecnologia ajudando a comunidade a melhorar a qualidade de vida através da técnica". 
Nesse contexto, esta proposta em curso, permitirá aos educandos e suas famílias, a partir do campo experimental da escola camponesa, o desenvolvimento de conhecimentos associados a práticas de convivência com o semiárido, com inclusão de tecnologias sociais, como o reúso de águas cinzas para os quintais produtivos. Dessa forma, uma verdadeira Escola do Campo estabelece vínculos com os sujeitos do campo, uma escola formadora humana que possibilita o desenvolvimento sustentável de reterritorialização do campo a partir de tecnologias sociais.

\subsection{O sistema de reúso das águas cinzas}

O sistema de reúso é formado por um conjunto de tubulação para captação de águas cinzas e distribuição para o sistema, caixa de gordura, responsável por reter parte dos resíduos sólidos, garfo de distribuição de água e dois tanques, assim como é mostrado na figura 4. Assim, o primeiro tanque é um filtro biológico destinado ao tratamento de águas cinzas e o segundo é o tanque de reúso de água, onde após o tratamento pelo filtro biológico, a água tratada passa por meio da gravidade para ele.

Além dessas partes, o sistema apresenta um conjunto motobomba movimentado a energia solar, com a finalidade de bombear a água já tratada para uma caixa d' água suspensa, onde será destinada, por gravidade, para canteiros de produção.

$\mathrm{E}$, também, para um minhocário com a finalidade de garantir o húmus necessário para manutenção do sistema. O filtro é composto por camadas de húmus, minhoca, serragem, areia lavrada, cascalhos, seixos. Todo o sistema implantado foi doado pela organização CETRA.Importa considerar que o sistema de reúso da escola está em processo de implementação para as aulas práticas e teóricas dos alunos no campo experimental e que no momento as aulas acontecem no formato remoto por conta da pandemia

No entanto, segundo o diretor, a escola está se preparando para retorno dos presenciais, principalmente para efetivar a proposta do campo que tem como uma das matrizes formativas o trabalho produtivo e que o desafio é integrar a proposta do reúso das águas cinzas no currículo escolar, integrando a parte diversificada (PSC, PEP e OTTP) com as áreas do conhecimento. Sobre essa questão, os sujeitos da pesquisa responderam as seguintes proposições:

Encontramos objetos de estudo na Química, na biologia, na matemática; a área e perímetro dos terrenos, a capacidade de armazenamento de água, em textos que produzidos dentro da língua portuguesa; os países que que falam língua estrangeira na via campesina e os sistemas de eco agroalimentares desses países, enfim; cada componente traz elementos que dialogam com essa temática (EDUCADOR(A) 1$)$.

Em OTTP pode ser trabalhado a parte técnica, onde o aluno aprenderá o funcionamento e a produção através do reúso, em PEP o aluno aprenderá a fazer pesquisas na área e escrever projetos baseados no reúso, e PSC serviria para difundir a tecnologia ajudando a comunidade a melhorar a qualidade de vida através da técnica (EDUCADOR (A) 2). 
Para que seja bem aproveitada, temos que pensar num calendário em que as disciplinas da base comum dialoguem com as diversificadas e facilite a interação entre as mesmas. O processo de planejamento coletivo também é outra coisa que tem que funcionar a contento (EDUCADOR (A) 3).

Percebe-se nessas questões acima, o desafio da integração curricular a partir de aulas teóricas-práticas no campo experimental e que todo o processo de ensino e aprendizagem esteja relacionado com os saberes da realidade. Ou seja, o conhecimento parte da realidade dos sujeitos do campo, onde a escola está inserida.

Um conhecimento construído pelos educandos para além dos muros da escola para a produção apropriada de tecnologias à melhoria de vida camponesa que segundo Plilippi Jr. (2000, p. 14) só um conhecimento interdisciplinar pode apontar soluções para problemas sociais e ambientais.

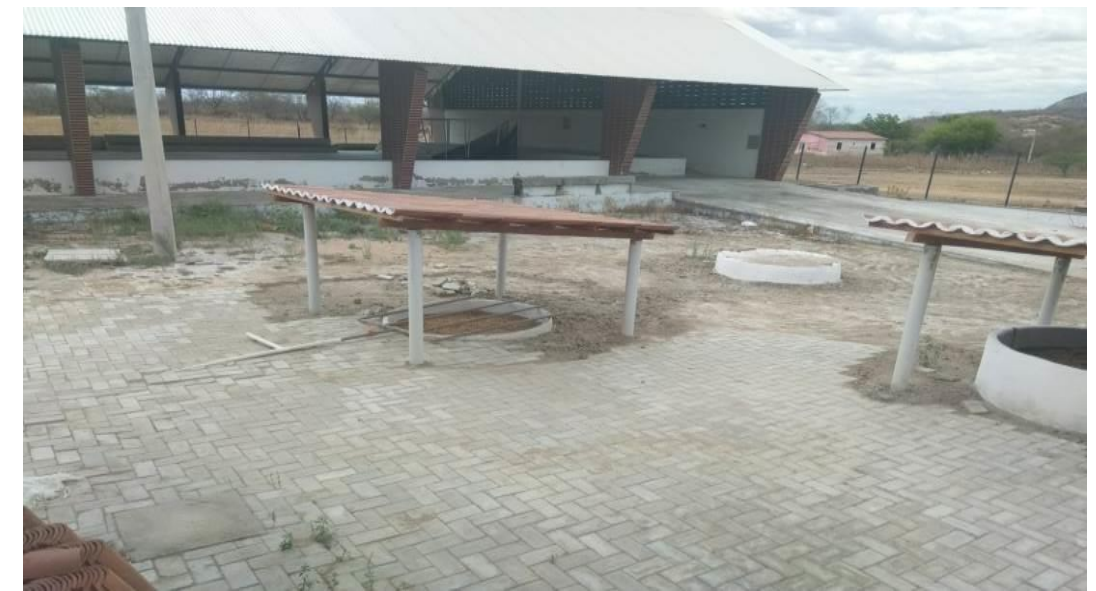

Figura 4: Filtro biológico e tanque de reúso da EEM do Campo Irmã Tereza Cristina.

Fonte: Os autores, 2021.

De acordo com Gouveia (2015), às águas que eram lançadas nos quintais sem tratamento e que contaminam os solos, agora poderão ser direcionadas para o plantio, constituindo-se assim, uma grande possibilidade de nutrição para as famílias camponesas, o que reverbera nas seguintes falas dos sujeitos da pesquisa sobre a importância dessa tecnologia de reúso das águas cinzas da escola no campo experimental na escola:

Trazendo economia de água, e isso vai impactar na economia e no meio ambiente. Subsidiar no cultivo de frutíferas; Subsidiar as plantas nos períodos secos; Ensinar práticas agroecológicas para os jovens (EDUCADOR (A) 1). Mostrando que o sistema funciona, e que eles podem produzir muito utilizando uma água que seria descartada, além de mostrar que seria uma tecnologia de baixo custo. Sendo assim a comunidade iria produzir alimentos saudáveis com um custo reduzido e sendo produzido no próprio quintal de casa (EDUCADOR (A) 2). Esse processo vai contribuir para o uso racional da água e consequentemente a produção de frutas, hortaliças e plantas medicinais para o consumo das famílias, o que representa uma melhoria na qualidade de vida dessas pessoas (EDUCADOR (A) 3 ). 
Percebe-se na fala do educador(a) 1 a questão ambiental que se reverbera na história humana segundo Khatounian, (2001, p. 18) "em que vários pontos do planeta e em várias épocas se acumularam conhecimento sobre formas mais sustentáveis de existência.". Já na fala dos educadores (as) 2 e 3 que se reverberam em Vendramini (2007) quando este pesquisador observa que "a educação do campo ganha um novo sentido, quando associada a um movimento social que defende a educação articulada com a criação de condições materiais para a vida no campo.

\section{Considerações Finais}

A proposta da utilização de águas cinzas no campo experimental da EEM Irmã Tereza apresenta-se como oportunidades e possibilidades para a produção de conhecimentos dos educandos contextualizado às condições de escassez de água no semiárido dos sertões de Quixeramobim, principalmente em área de assentamento rural onde a luta por reterritorialização da cultura e da identidade camponesa é um desafio constante. E que o campo experimental da agricultura camponesa abre possibilidades em que o processo pedagógico de ensino e pesquisa se vincula às condições materiais de existência das famílias do assentamento e, também, que o conhecimento é produzido a partir dos sujeitos em que a escola está inserida.

Além do mais, conclui-se, que o reúso de águas cinzas oriundas das casas é uma alternativa como mais uma tecnologia para a convivência no semiárido, aumentando a disponibilidade hídrica para a produção de alimentos nos quintais produtivos nos territórios das famílias camponesas, $e$ isso se reverbera na qualidade de vida das famílias em uma região em que as condições climáticas não favorecem com chuvas irregulares e concentradas e grande evaporação. Então, o maior desafio das famílias está na gestão da escassez de água, principalmente para a produção de alimentos nos seus quintais produtivos.

Portanto, a proposta da escola para o reúso das águas cinzas no campo experimental, além de possibilitar estudos e pesquisas acadêmicas dos alunos, possibilitará que essa tecnologias esteja a serviço da valorização dos processos produtivos e segurança alimentar das famílias.

\section{REFERÊNCIAS}

ALCÓVER, Juan Carlos Alvarado et al. PINTO. Tecnologias Sociais como Alternativa na Convivência com o Semiárido. ALCÓVER, Juan Carlos Alvarado; FONSECA, Aluísio Marques da; PINTO, Olienaide Ribeiro de Oliveira. (Orgs).

Convivência com o Semiárido. Fortaleza: Imprece, 2020.

ALTIERI, Miguel. Agroecologia: a dinâmica produtiva da agricultura sustentável. 4a. Ed. Porto Alegre: Editora da Universidade/UFRGS, 2004.

AQUINO, Joacir Rufino de.; ALVES, Maria Odete; VIDAL Maria de Fátima. Agricultura Familiar no Nordeste do Brasil: um retrato atualizado a partir dos 
dados do censo agropecuário. 2017. Rev. Econ. NE, Fortaleza, v. 51, suplemento especial, p. 31-54, agosto, 2020. Disponível em: https://www.bnb.gov.br/revista/index.php/ren/article/view/1271. Acesso em: 20 mar. 2021.

BRASIL. Ministério da Educação. Diretrizes Operacionais para a Educação Básica nas Escolas do Campo: Resolução CNE/CEB, n. 1, de 3 de abril de 2002. Brasília. Disponível em:

http://portal.mec.gov.br/cne/arquivos/pdf/CEB012002.pdf . Acesso em: 10 mai. 2021.

BRASIl. Ministério da Educação. Secretaria da Educação Fundamental. Programa Parâmetros em Ação Meio Ambiente na Escola. Guia do Formador. Brasília, DF, 2001.

BRASIL. Governo do Estado do Ceará/ Secretaria de Educação. EEM do Campo Irmã Tereza Cristina. Disponível em:

https://crede12.seduc.ce.gov.br/index.php/component/content/article/109endereco-escolas/\%20881-eem-do-campo-irma-tereza-cristina. Acesso em: 22 mar. 2021.

BRASIL. Decreto no 7.352 de 04 de Novembro de 2010. Disponível em: http://www.planalto.gov.br/ccivil_03/_ato2007-2010/2010/decreto/d7352.htm , Acesso em: 22 mar. 2021.

CALDART, Roseli Salete. Por uma Educação do Campo: traços de uma identidade em construção. In: KOLLING, Edgar Jorge; CERIOLI, Paulo Ricardo; CALDART, Roseli Salete (Orgs.). Educação do Campo: identidade e políticas públicas. Brasília, DF: Articulação Nacional por uma Educação do Campo, 2002. v. 4. (Coleção por uma Educação do Campo).

CALDART, Roseli Salete. A Escola do Campo em Movimento. Coletivo Nacional de Educação do MST. Instituto Técnico de Capacitação e Pesquisa da Reforma Agrária (ITERRA) - Brasil, 2003. Currículo sem Fronteiras, v.3, n.1, pp.6081, Jan/Jun 2003. Disponível em:

http://www.ia.ufrrj.br/ppgea/conteudo/conteudo-2009-1/EducacaoMII/3SF/A_ESCOLA_DO_CAMPO_EM_MOVIMENTO.pdf . Acesso em: 20 jun. 2021.

CALDART, Roseli Salet. Educação do Campo: notas para uma análise de percurso. Trab. Educ. Saúde, Rio de Janeiro, v. 7 n. 1, p. 35-64, mar./jun.2009. Disponível em:

https://www.epsjv.fiocruz.br/upload/d/Caldart.pdf. Acesso em: 15 de mar. 2021.

CEARÁ. Assembleia Legislativa do Estado do Ceará. Cenário Atual dos Recursos Hídricos do Ceará. Conselho de Altos Estudos e Assuntos 
Estratégicos. SANTANA, Eudoro Walter (Coordenador). INESP. Fortaleza, 2008

CEARÁ. Política Estadual de Educação Ambiental. Lei.14.892. Disponível em: https://www.sema.ce.gov.br/politica-estadual-de-educacao-ambiental/. Acesso em: 15 mai. 2021.

COSTA, İtalo Benevides; BESSA, Carlos Vinícius Damasceno. Estudo de Viabilidade da Implantação do Filtro Bioágua para Reaproveitamento das Águas Cinzas nos Domicílios da Zona Urbana da Cidade de Caraúbas/RN. Disponível em: https://repositorio.ufersa.edu.br/bitstream/prefix/3011/2/ITALOBC_ART.pdf. Acesso em: 16 jun. 2021.

CONTI, Irio Luiz; PONTEL, Evandro. Transição paradigmática na convivência com o Semiárido In: Convivência com o Semiárido Brasileiro. Autonomia e Protagonismo Social. CONTI, Irio Luiz; SCHROEDER, Edini Oscar. (Orgs.) Editora IABS, 2013.

DEMO, Pedro. Metodologia do conhecimento científico. São Paulo: Atlas, 2000.

FIORI, Simone; FERNANDES, Vera Maria Cartana; PIZZO, Henrique. Avaliação qualitativa e quantitativa do reúso de águas cinzas em edificações. 2006. Disponível em: https://seer.ufrgs.br/ambienteconstruido/article/view/3676. Acesso em: 25 jun. 2021.

FREIRE, Paulo. Pedagogia da Autonomia: saberes necessários à prática educativa. São Paulo: Paz e Terra, 1996

FONSECA JÚNIOR, Wilson Corrêa. Análise de Conteúdo. In: DUARTE, Jorge.; BARROS, Antonio. (Orgs.). Métodos e Técnicas de Pesquisa em

Comunicação. 2a. Ed. São Paulo: Atlas, 2011. p. 280-303

GUIMARÃES, Mauro. Sustentabilidade e Educação Ambiental. In: A Questão Ambiental: diferentes abordagens. CUNHA, Sandra Baptista; GUERRA, Antonio José, (Org). São Paulo: Bertrand Brasil, 2009.

GIL, Antonio Carlos. Como elaborar projetos de pesquisa. $4^{a}$. Ed. São Paulo: Atlas, 2002.

GODOY, Arilda Schmidt. Pesquisa qualitativa. Tipos fundamentais. Revista de Administração de Empresas. São Paulo, 1995. 
GOUVEIA, Adriana Ribeiro. Projeto: Segurança Alimentar para o

Semiárido de Pernambuco. Sistema de Bioágua Familiar. Manual de utilização do sistema. AVSI Brasil. Recife, Outubro de 2015.

HISTÓRIA DA ESCOLA DO CAMPO DE ENSINO MÉDIO IRMÃ TEREZA CRISTINA. EEM do Campo Irmã Tereza Cristina. Assentamento Nova Canaã - Ceará, 2021

ILCA. INSTITUTO INTERAMERICANO DE COOPERAÇÃO PARA A AGRICULTURA. Semeando saberes, inspirando soluções: boas práticas na convivência com o semiárido. Reúso de águas cinzas. Salvador, 2017.

LIMA, Vera Lúcia Antunes de; GUERRA, Hugo Orlando Carvallo. Técnicas Alternativas de Captação e Reúso de Água em Áreas Agrícolas. In: Difusão de Tecnologias Apropriadas para o Desenvolvimento Sustentável do Semiárido. FURTADO, Dermeval Araújo; BARACUHY. José Geraldo de Vasconcelos Baracuhy; FRANCISCO, Paulo Roberto Megna. (Orgs.). Campina Grande, 2013.

LOPES, Riuzuani Michelle Bezerra Pedrosa et al. Técnicas Alternativas de Captação e Reúso de Água em Áreas Rurais. In: Difusão de tecnologias apropriadas para o desenvolvimento sustentável do semiárido brasileiro. FURTADO, Dermeval Araújo; BARACUHY José Geraldo de Vasconcelos. FRANCISCO, Paulo Roberto Megna. (Orgs.). Campina Grande, 2013.

PROJETO BIOÁGUA: REUSO DAS ÁGUAS CINZAS PARA PRODUÇÃO DE ALIMENTOS NO SEMIÁRIDO Experiência da Escola de Ensino Médio do Campo Florestan Fernandes - Assentamento Santana. Monsenhor Tabosa-CE, 2020.

PROJETO POLÍTICO PEDAGÓGICO - PPP. Escola de Ensino Médio do Campo Florestan Fernandes. Assentamento Santana. Monsenhor Tabosa, Ceará, 2019.

PROJETO POLÍTICO PEDAGÓGICO - PPP. EEM João dos Santos de Oliveira. Assentamento 25 de Maio. Madalena, Ceará, 2020.

KHATOUNIAN, Carlos Armênio. A reconstrução ecológica da agricultura. Botucatu, SP: Agroecológica, 2001.

MALVEZZI, Roberto. SEMI-ÁRIDO: Uma Visão Holística. CONFEA-CREA,2007.

MILLER JR, George Tyler. Ciência Ambiental. 11a. Ed. São Paulo: CENGAGE Learning, 2012. 
MOLINA, Mônica Castagna; FREITAS, Helana Célia de Abreu. Avanços e Desafios na Construção da Eduação do Campo. Em Aberto, Brasília, v. 24, n. 85, p. 17-31, abr. 2011.

NETO, Manoel Pereira da Silva; SALLES, Maria Gorete Flores; PINTO, Olienaide Ribeiro de Oliveira; SANTOS, Luzivone da Silveira do Nascimento. Plantas Medicinais nos Quintais Urbanos da Comunidade Alto da Cruz no Pitú em Baturité-CE. Enciclopédia Biosfera, Centro Científico Conhecer - Goiânia, v.16 n.29; p.1212, 2019. Disponível em:

https://conhecer.org.br/ojs/index.php/biosfera/article/view/267. Acesso em: 21 jun. 2021.

PEDROSA, Rosângela Aparecida. A importancia dos quintais produtivos na economía familiar.2016. Disponível em:

https://www.cpao.embrapa.br/cds/agroecol2016/PDF's/Minicurso.Oficinas/Mini curso-\%20Rosangela\%20Pedrosa-\%20QUINTAIS\%20PRODUTIVOS.pdf .

Acesso em: 04 set. 2021.

PEREIRA, Karla Raphaella Costa; COSTA, Frederico Jorge Ferreira.; DE PAULA, Alisson Slider do Nascimento. Escolas de Ensino Médio do Campo no

Ceará: dialética na formação dos professores. Curitiba, 2020.

PINTO, Olienaide Ribeiro de Oliveira et al. Tecnologias Sustentáveis na Convivência com o Semiárido. In: Convivência com o Semiárido. ALCÓVER, Juan Carlos Alvarado; FONSECA, Aluísio Marques da; PINTO, Olienaide Ribeiro de Oliveira. (Orgs.) Fortaleza: Imprece, 2020.

PHILIPPI JÚNIOR, Arlindo. A Interdisciplinaridade como atributo da C \& T. In: Interdisciplinaridade em Ciências Ambientais. PHILIPPI JÚNIOR, Arlindo; TUCCI, Carlos E. Morelli; HOGAN, Daniel Joseph; NAVEGANTES, Raul. (Orgs.). São Paulo: Signus Editora, 2000.

SANTIAGO, Fábio et al. Manual de Manutenção e Manejo do Sistema Bioágua Familiar. Reúso de água cinza doméstica para a produção de alimentos na agricultura familiar do semiárido brasileiro. Caraúbas-RN, ATOS, 2015.

SACHS, Ignacy. Estratégias de transição para o século XXI. In: Para Pensar o Desenvolvimento Sustentável. Bursztyn, Marcel (Org). IBAMA - ENAP. Editora Brasiliense, 1993. 
SANTOS, Edinéia Oliveira. NEVES, Márcia Luzia C. Educação do Campo e Desenvolvimento Territorial: reflexões e propostas. Caderno Temático IV Educação do Campo e Desenvolvimento Territorial. Edição No 06, V 1, Ano III (2012). Disponível em: https://www2.ufrb.edu.br/revistaentrelacando/index.php/edicoesentrelacando/42-desenvolvimento-06. Acesso em: 21 jun. 2021.

\section{SILVA, Maria Ellany Damasceno et al. Acesso à Água e Produção de}

Alimentos. O Impacto das Cisternas em Ibaretama, Ceará. Atena, 2020.

SILVA, Francisco Erivan da; SILVA, Maria Eliza Leite; ASSUNÇÃO, Marcella de Sá Leitão. Eficiência do sistema bioágua no tratamento de águas cinzas. ESF. V Congresso Brasileiro dos Engenheiros Sem Fronteiras. Natal - R, 2018. Disponível em: https://doity.com.br/anais/cbesf2018/trabalho/68574 . Acesso em: 20 jun. 2021.

SISTEMATIZAÇÃO DO CAMPO EXPERIMENTAL. EEM João dos Santos de Oliveira. Assentamento 25 de Maio. Madalena - Ceará, 2021

VENDRAMINI, Célia Regina. Educação e Trabalho: Reflexões em Torno dos Movimentos Sociais. 2007. Disponível em:

https://www.scielo.br/j/ccedes/a/w5LkbYSPx79vwG4GDk6HkZL/?lang=pt\&for mat=pdf . Acesso em: 29 de jun. 2021.

VIANA, Cláudia Maria de Pontes et al. Perfil municipal das Cidades. IPECE. Quixeramobim - CE, 2017. 